\title{
THE SEQUENTIAL CHANGE OF A NAPHTHALENE- INDUCED BRONCHIOLAR DAMAGE AND OF PULMONARY CYTOCHROME P-450 IN MICE
}

\author{
Takahiko Harada and Mari Iwakuma \\ Biological Laboratory. Nippon Veterinary \& Zootechnical College \\ Tomoko Kirisawa, Mariko Nagane, and Jun Hatanaka \\ Department of Toxicology. Agricultural Chemical Institute, Nihon Tokushu Noyaku Seizo K.K. \\ Makoto Enomoto \\ Department of Pathology. Biosafety Research Center
}

\begin{abstract}
Male ICR mice were exposed to $2 \mathrm{mmol} / \mathrm{Kg}$ body weight of naphthalene by single intraperitoneal injection. Treated mice were killed consecutively from 2 hours to 14 days after treatment. Tissues were examined for alterations of the bronchiolar epithelial cells by light and electron microscopes, and for amount of pulmonary cytochrome P-450 by ascorbate PES method.

Morphologically, naphthalene caused a remarkable increase in smooth-surfaced endoplasmic reticulum of the Clara cells within 4 hours after treatment and the subsequent lesions including the exfoliated ciliated cells. Foamy cell-like Clara cells were observed in the bronchiolar lumen from 6 to 24 hours followed by a pronounced increase in number of flat ciliated cells covering the denuded surface of the bronchiolar tree $\mathbf{4 8}$ hours after treatment. These lesions were almost completely recovered 7 days after treatment.

The amount of pulmonary cytochrome P-450 increased promptly and reached up to the maximum level 4 hours after treatment. paralleling with the remarkable increase in smooth surfaced endoplasmic reticulum of the Clara cells. Thereafter. cytochrome $\mathbf{P}-\mathbf{4 5 0}$ showed a decrease in amount simultaneously with degeneration and desquamation of the Clara cells and reduced by $40 \%$ of control amount 24 hours after treatment. There results seem to show that the activity of cytochrome P-450 is closely related with smooth surfaced endoplasmic reticulum of the Clara cells, and naphthalene-induced pulmonary damage is mediated by cylochrome P-450. (J Toxicol Pathol 1 : 137 142, 1988)

Key words: Naphthalene, Bronchiolar damage, Cytochrome P-450
\end{abstract}

\section{Introduction}

Naphthalene (NP) is an important intermediate which is used as a dye and antioxidant. It is a major component of moth balls and has been used for insect and parasite elimination.

NP is known to damage selectively the nonciliated bronchiolar epithelial cells : C.lara cells of

\section{原田隆彦 岩熊真理 桐沢朋子長根万律子㚼中純}

椵本 真

Accepted for publication : August 31, 1988

Mailing address: Takahiko Harada, Biological Laboratory. Nippon Veterinary and Zootechnical College. Kyonan-cho, Musashino-shi. Tokyo 180. Japan. the lung in the mouse ${ }^{1.2}$. The recent papers ${ }^{3,4}$ on the sensitivity to several toxic chemicals of the Clara cells containing high levels of cytochrome P-450 enzymes ${ }^{5}$, have evoked attention on these cells as a target of xenobiotics ${ }^{6}$.

There have been several studies on NP-induced lung damage in mice ${ }^{7-10}$, but its early ultrastructural alterations have not been fully studied. The present study was carried out to disclose a correlation of NP-induced damage to the Clara cell with the activity of pulmonary cytochrome $\mathrm{P}$ 450 in mice. 


\section{Materials and Methods}

Male ICR mice weighing 26 to $35 \mathrm{~g}$ received a single intraperitoneal injection with $2 \mathrm{mmol} / \mathrm{Kg}$ naphthalene (NP) dissolved in corn oil.

\section{Morpholog.'}

Mice were sacrificed under anesthesia using pentobarbital 2, 4. 6, 12, and 24 hours and 2, 7, and it dis, after treatment, respectively. The trachea was rapidly excised. and the fixative was injected through a silicone cannula inserted in the trachea. Lung expansion "av easily achieved with 8 to 10 $\mathrm{cm}$ water pressure.

\section{Lighı microscop.'}

Each three animals were examined at the time of sacrifice. Buffered formalin solution of $10 \%$ " as used as a fixative. The lungs were cul and fixed overnight in the same fixative. The tissue specimen was prepared b! the regular way

\section{Eleciron microscop:}

Each two animals were examined at the time of sacrifice. 2.5"i glutaraldehyde solution in 0.1 $M$ phosphate buffer was used as a fixative. The lung were cut into $1 \mathrm{~mm}^{3}$ strips and fixed in the same fivalive. The strips were rinsed in $0.1 \mathrm{M}$ phosphate buffer and post-fixed with $1 \%$ osmium tetroxide. dehydrated by passage through a graded series of concentration of ethanol and acetone. and embedded in epon-araldite. Ultrathin sec- tions were cut, stained with uranyl acetate and lead citrate and examined with JEM $100 \mathrm{CX}$-II electron microscope.

Measurement of cylochrome P-450

Mice were sacrificed 0 (control), 2, 4, 6, 24 hours after the treatment. Each 40 animals were used for each pool of lungs at the time of sacrifice and pulmonary microsomes were prepared by the method using calcium aggregation". Cytochromes P-450 were measured by the method of ascorbate-PES ${ }^{12}$.

\section{Results}

Pulmonary cytochrome P-450 showed an increase in amount 2 hours after the treatment of naphihalene (NP) and reached to the maximum (1. 6 times of control) 4 hours after the treatment. Thereafter, P-450 showed a gradual decrease and reduced by $37 \%$ of the normal amount 24 hours after the treatment (Fig. 1).

\section{Morphology'}

Light microscopy: Terminal bronchioles are composed of two types of cells; ciliated cell and nonciliated : Clara cell. These two cells are easily distinguished in the control lungs.

In the NP-treated mice, Clara cells showed a swelling of cytoplasm from 2 to 4 hours after the treatment. Degeneration or necrosis of the Clara cells with subsequent change looking like a foamy

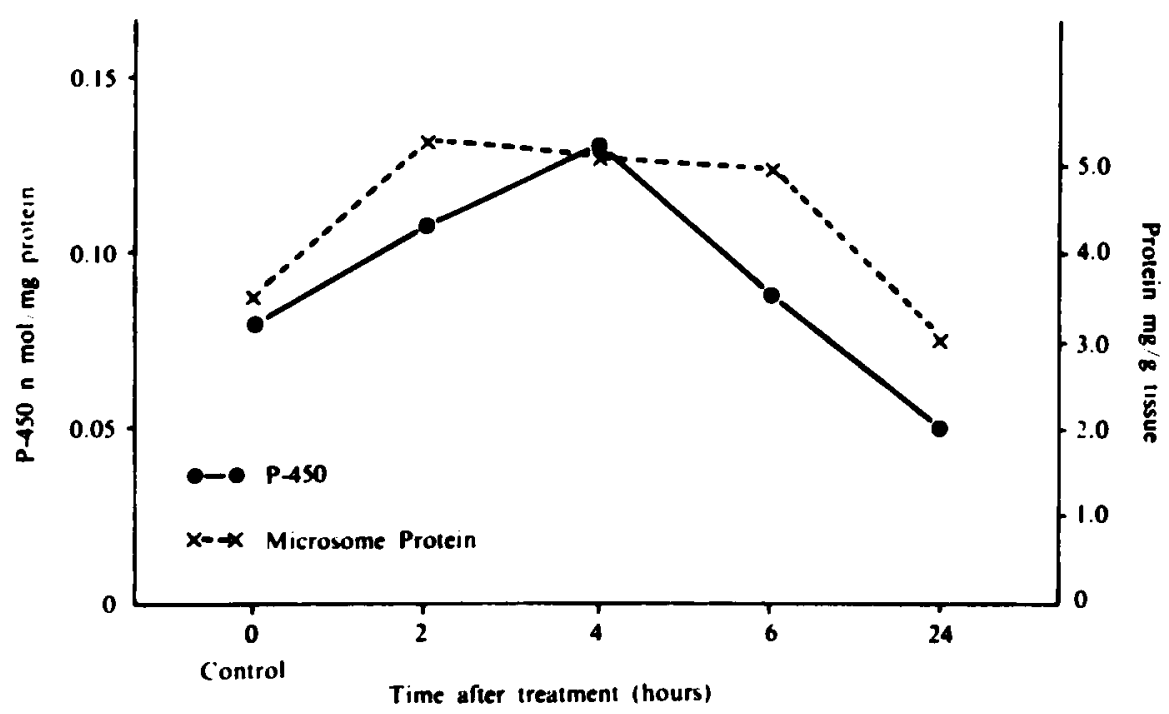

Fig. I. Levels of cytochrome P-450 in lung microsomes obtained from control and naphthalene (NP)treated mice. 


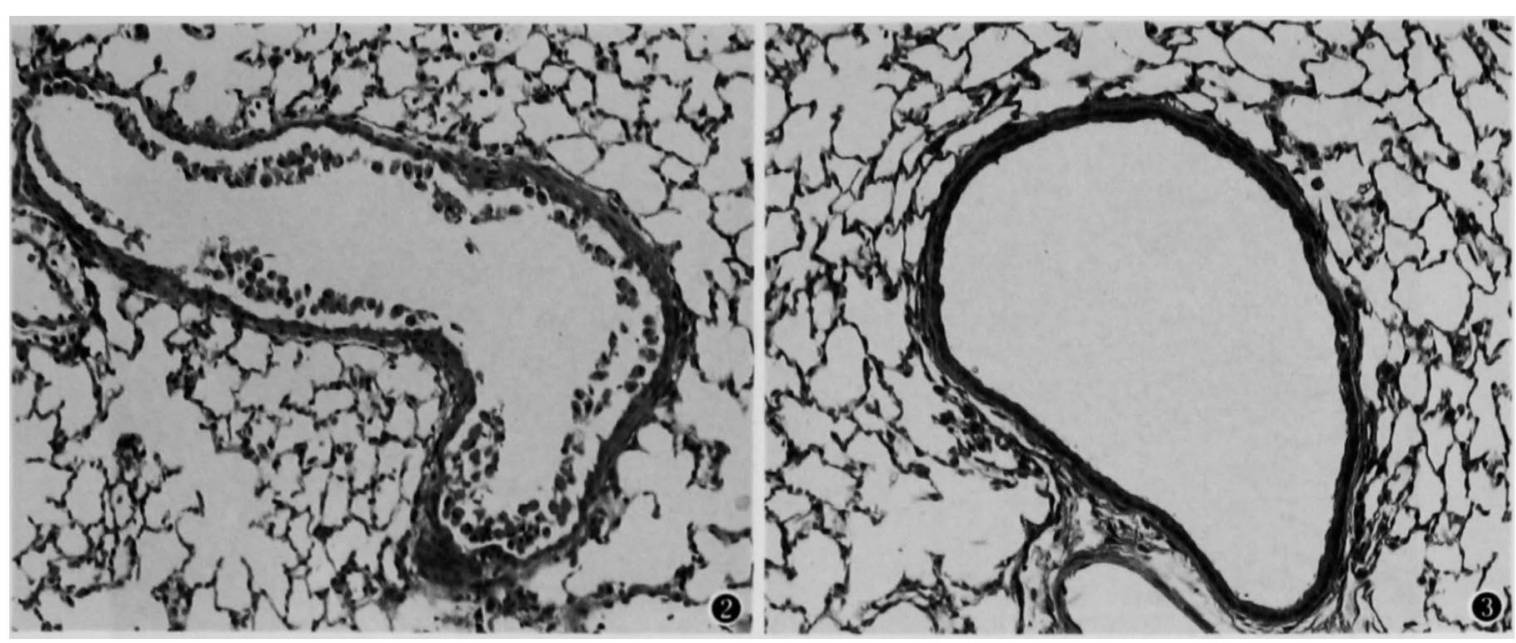

Fig. 2. Light micrograph. 12 hours after treatment with NP. An accumulation of exfoliated Clara cells is seen as a debris in the bronchiolar lumen. (H.E., $\times 80$ )

Fig. 3. 24 hours after treatment with NP. Bronchiolar wall is seen lined with flat ciliated cell. (H.E., $\times 80)$

cell and exfoliation of the ciliated cells in the bronchiolar lumen were seen 6 hours after the treatment. These alterations were also observed up to 24 hours after the treatment. Especially, an accumulation of the exfoliated Clara cells was seen as a debris in the bronchiolar lumen (Fig. 2). Gradual increase in number of flat ciliated cells on the surface of bronchiolar tree was seen $\mathbf{4 8}$ hours after the treatment (Fig. 3). Bronchiolar epithelium was almost completely recoverd 7 days after the treatment.

Electron microscopy ; Clara cells are columnar in shape. There are abundant smooth surfaced endoplasmic reticulum (SER) in their cytoplasm. The center of the Clara cell is occupied by the nucleus dividing cytoplasmic zones. The basal zone contains rough surfaced endoplasmic reticulum (RER) and mitochondria with scanty cristae. The upper zone contains many mitochondria similar to those in the basal zone and secretory granules with high density. Ciliated cells are columnar with poor organellae compared with Clara cell (Fig. 4).

In the naphthalene treated mice, the Clara cells showed a swelling of the cytoplasm with the increase in SER and circular vacuoles. However, RER was decreased 2 hours after the treatment (Fig. 5). The enlarged vacuoles increased with the other vacuoles formed by expansion of the antrum of SER 4 hours after the treatment. The cytoplasm was occupied by SER and concentric lamellar bodies composed of SER also appeared therein (Fig. 6). Vacuolated Clara cells similar to foamy cells with decreased SER appeared 6 hours after the treatment (Fig. 8). The exfoliating cells, debris, and macrophage were seen scattered in the bronchiolar lumen because of damage of the Clara cells occurring 12 hours after the treatment. Flat ciliated cells of bronchiolar epithelium-origin were observed in this stage (Figs. 9 and 10). A part of the bronchi was denuded by the loss of epithelial cells 12 hours after the treatment (Fig. 9). However, mitosis (Fig. 7) and proliferation of the bronchiolar epithelium were seen 48 hours after the treatment. The bronchioli were indistinguishable from those of the control lungs by 7 days. No debris was seen in the lumen of the bronchioli.

\section{Discussion}

Naphthalene (NP) is known to damage selectively the Clara cells of lung in mice ${ }^{1,2}$. And the enzyme of cytochrome $\mathbf{P}-\mathbf{4 5 0}$ has been suggested to be highly localized in these cells ${ }^{5}$. This study was carried out to disclose a correlation of NP-induced damage of the Clara cells with the activity of pulmonary cytochrome $\mathbf{P}-\mathbf{4 5 0}$ in mice.

Intraperitoneal injection of NP caused a remarkable proliferation and dilatation of the smooth surfaced endoplasmic reticulum (SER) in the Clara cells. Their alterations have been 

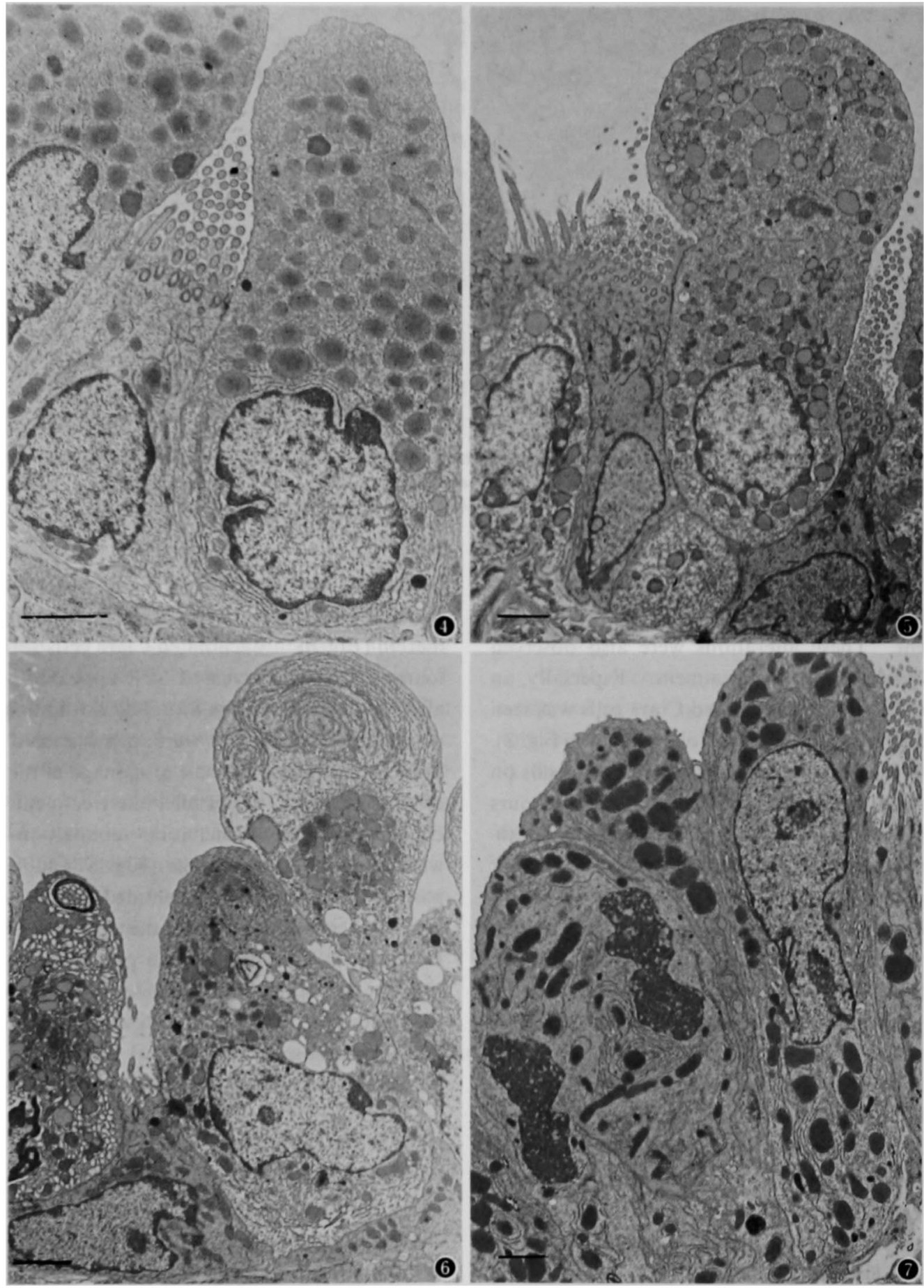

Fig. 4. Electron micrograph. Ciliated cell and Clara cells from control mouse. $*$ bar $=2 \mu \mathrm{m}$

Fig. 5. 2 hours after treatment with NP. Clara cell shows swelling of the cytoplasm with an increase in number of SER.

Fig. 6. 6 hours after treatment with NP. CLB and circular vacuoles are found in cytoplasm of Clara cells.

Fig. 7. 48 hours after treatment with NP. Mitosis in Clara cell. 

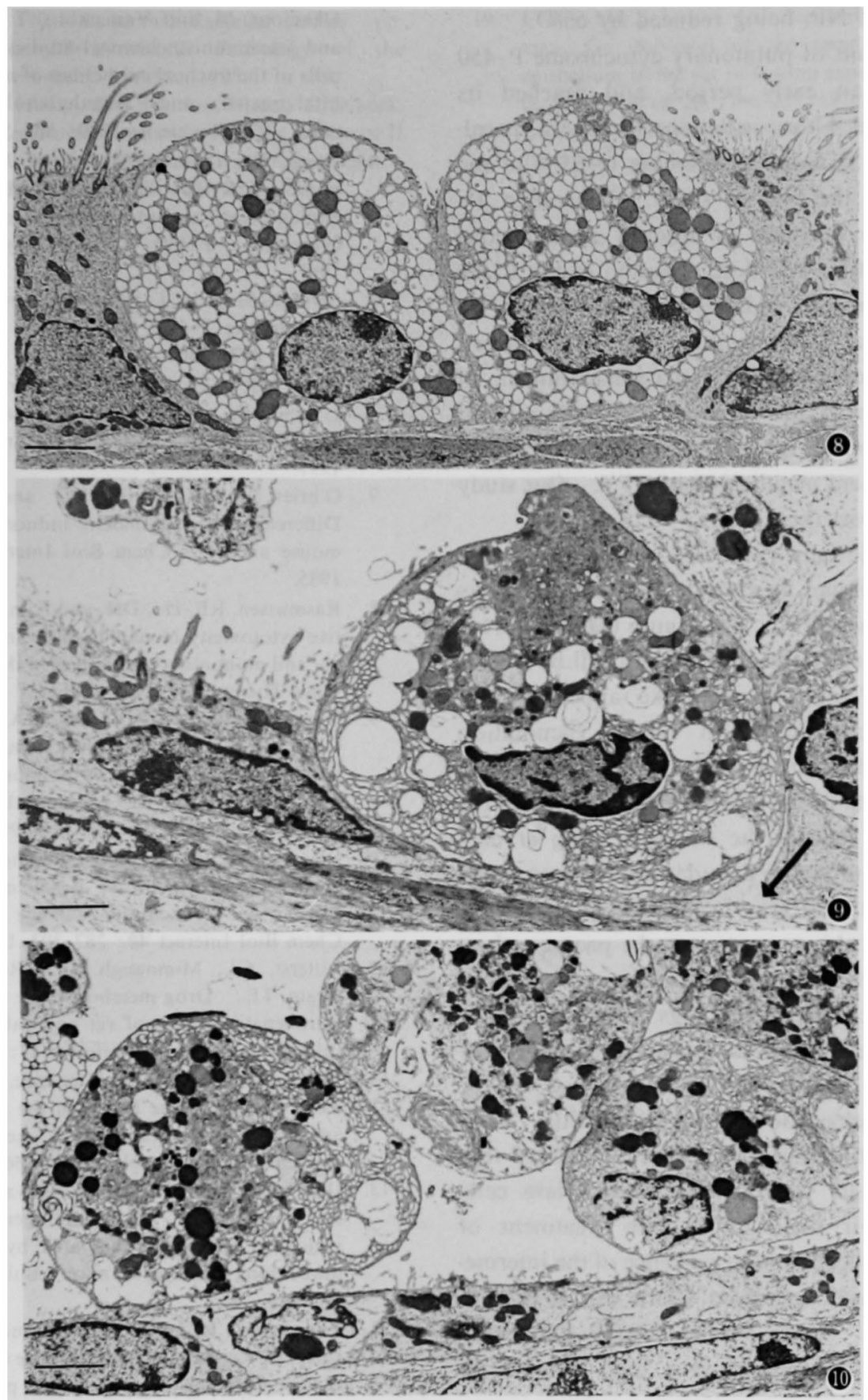

Fig. 8. 6 hours after treatment with NP. Vacuolation of Clara cells like foamy cells and ciliated cells are seen.

Fig. 9. 12 hours after treatment with NP. Flat ciliated cell is replacing damaged Clara cells. A part of the basement membrane in denuded (arrow).

Fig. 10. 12 hours after treatment with NP. Exfoliation of Clara cells is seen as a debris in the lumen.

known to be induced by various lung toxins, such as butylated hydroxytoluene (BHT) ${ }^{13.14}$ and PCB $^{15}$. Tong et al. examined the morphological change and mixed function oxidase activity of lungs 24 hours after the treatment of NP in mice. They reported that cytochrome $P-450$ was most sensitive 
to the effect of NP. being reduced by $65 \%$.

The amount of pulmonary cytochrome P-450 increased at an early period, and reached its maximum level 4 hours after the treatment. paralleled with the remarkable increase in SER of the Clara cells in the present study. Thereafter, P45) showed a decrease in amount simultaneous with degeneration and desquamation of the Clara cells. These results indicate that cytochrome P450 localized at SER membrane of the Clara cell plays an important role in drug metabolism of lung. Warren et al. reported that NP-induced pulmonary damage is mediated by the cytochrome P-450-dependent metabolism of NP10. Our study seem, to support their vieu,

Concentric lamella bodies (CLB) are known to appear in tissues by various mechanisms induc. ing carcinogenesis ${ }^{16,17}$. This figure is formed from SER and observed also in the Clara cell by $\mathrm{BHT}^{13}$ or adrenalin's. Foamy cell-like appearance of the Clara cells seems to reflect vacuolation produced by dilation of SER.

Whole area of the bronchi was denuded by the loss of Clara cells in the study of Tong et al.?. However, in our study, denudation was seen focally at the trasitional area from bronchi to alveoli. Denudation at this area seems to be progressed on the basement membrane of the Clara cells replaced with the flat ciliated cells (Figs. 9 and 10). The flat ciliated cell seem to represent a reparatory change of the bronchiolar cells followed by the subsequent regeneration of the Clara cells. Contrary to these findings. Evans et al. suggested that the ciliated cells were derived from Clara cells based on their observation with treatment of $\mathrm{NO}_{2}{ }^{19}$. Ebe suggested the existence of the intermediate cell transferring from Clara cell to type II alveolar cell ${ }^{20}$. These studies suggest that bronchiolar epithelial cells have a high potency in differentiation.

\section{References}

I. Mahvi, D. Bank. H. and Hariey, R: Morphology of a naphthalene-induced bronchiolar lesion. Am J Pathol 86 : 559-572. 1977.

2. Reid, WD, Het, KF. Glick, JM, and Krishna, G : Metabolism and binding of aromatic hydrocarbons in the lung. Am Rev Resp Dis 107 : 539-551. 1973.

3. Ishimura, K, Usa, M. Fujita, H. Kawata, S,
Okamoto, $M$, and Yamamoto, T: Ultrastructural and immunohistochemical studies on non-ciliated cells of the tracheal epithelium of normal. phenobar. bital-treated, and 3-methylcholantheren-treated mice. Cell Tissue Res 240: 501-504, 1985

4. Keith, IM. Olson, EB. Jr. and Jefcoat. RJ : Immunological identification and effects of 3-methlcholantherene and phenobarbital on rat pulmonary cytochrome P-450. Cancer Res 47: 1878-1882, 1987.

5. Serabjit-Singh, CJ, Walf, CR, and Philpot, RM : Cytochrome P-450: Localization in rabbit lung. Science 207: 1469-1470, 1980.

6. Boyd. MR : Evidence for the clara cell as a site of cytochrome P-450-dependent mixed function oxidase activity in lung. Nature 269: 713-715, 1977.

7. O'brien, KAF, Smith, LL. and Cohen, GM: Differences in naphthalene-induced toxicity in the mouse and rat. Chem Biol Interact 55: 109-122. 1985.

8. Rasmussen, RE. Do. DH, and Kim. TS : Comparative cylotoxicity of naphthalene and its monomethyl-and mononitro-derivatives in the mouse lung. J Appl Toxicol 6: 13-20. 1986.

9. Tong. SS, Hirokata, Y, Trush, MA, Mimnaugh, EG, Ginsburg. E, Lowe, MC, and Gram. TE : Clara cell damage and inhibition of pulmonary mixed-function oxidase activity by naphthalene. Biochem Biophys Res Commun 100 944-950, 1981.

10. Warren. DL, Brown, DL. JR, and Buckpitt, AR Evidence for cytochrome P. 450 mediated metabolism in the bronchiolar damage by naphthalene. Chem Biol Interact 40 : 287-303. 1982.

11. Litterst. CL. Mimnaugh. EG, Reagan. RL. and Gram. TE: Drug metabolism by microsomes from extrahepatic organs of rat and rabbit prepared by calcium aggregation. Life Sci 17 : 813-818. 1975.

12. Johanneses. KAM and Depierre. JW: Measurement of cytochrome $P-450$ in the presence of large amounts of contaminating hemoglobin and methemoglobin. Anal Biochem 86: 725-732. 1978.

13. Harada, T. In akuma. M. Kirisaua, T, Nagane. M, and Hatanaka, J: Morphogenesis and toxicological aspects of butylated hydroxytoluene-induced lung damage in mice. Bull $N$ Z $\quad 36$ : 107-113. 1987.

14. Rasmussen. RE, Witte, ME, and Anderson, J : Effect of butylated hydroxytoluene (BHT) and naphthalene (N) on $3 \mathrm{H}$-benzo (a) pyrene (3H-BaP) metabolism in mouse lung. Proc Am Assoc Cancer Res 22 : $101,1981$.

15. Yamamoto. T. Wasano, K, Imayama, S, and Fujita, $M$ : An electron microscope study on the PCBinduced ultrastructural changes of the bronchiolar epithelium (in Japanese). Fukuoka Acta Med 72 : 216-222, 1981.

16. Emmelot, $P$ and Benedecti. EL: Changes in the fine structure of rat liver cell, brought about by dimethylnitrosamine. J Biophys Biochem Cytol 7 : 393-395, 1960. 
17. Ghadially, FN: Concentric lamellar bodies. pp. 266-271. In : Ultrastructural Pathology of the Cell. Butterworths, London, 1975.

18. Wang. NS. Huang. SN, Sheldon, $H$, and Thurlbeck, WM: Ultrastructural change of clara and type II alveolar cell in adrenalin-induced pulmonary edema in mice. Am J Pathol 62: 237-252, 1971.
19. Evans, MJ, Johnson, LV, Stephens, RJ, and Freeman, G: Renewal of the terminal bronchiolar epithelium in the rat following exposure to $\mathrm{NO}_{2}$ or $O_{3}$. Lab Invest $35: 246-257,1976$.

20. Ebe, $T$ : Ultrastructure of distal air way (in Japanese). Saibo 12 : 12-16, 1980. 